\title{
Effect of Slope on Control of Smoke Flow in Tunnel Fires
}

\author{
YAJUE WU, J.P. STODDARD and P. JAMES \\ Department of Mechanical \& Process Engineering \\ Sheffield University \\ Sheffield S1 3JD, UK \\ G.T. ATKINSON \\ Health and Safety Laboratory \\ Harpur Hill, Buxton, UK
}

\begin{abstract}
The value of the critical velocity to create a safe route upstream clear of smoke in the event of a tunnel fire is one of the prime important criteria for the design of the emergency ventilation system for road tunnels. For a tunnel with downhill slope, a greater critical velocity than that in a corresponding horizontal tunnel is required to control the smoke movement. The effect of the tunnel slope on the critical velocity has not been studied experimentally in connection with tunnel fires. This work concerns the examination of the effect of tunnel slope. A series of experimental tests has been carried out using a small model tunnel with downhill slopes between $0^{\circ}$ and $10^{\circ}$. The critical velocities and the ventilation velocities required to control the length of the "back-layering" smoke flow to 1 , 3,5 and 10 times of the tunnel heights were measured systematically. A slope correction factor to modify the effect of the downhill slope on the critical velocity has been proposed from the experimental results. The characteristics of the smoke flow in the upstream of the tunnel is discussed, and there is also a brief discussion on the effect of the bulk temperature of the smoke flow. These results extend the work of Oka and Atkinson [7] on smoke control in horizontal tunnels.
\end{abstract}

KEYWORDS: Tunnel fires, sloping tunnel, smoke flow, critical velocity.

\section{INTRODUCTION}

It is observed that smoke, hot gases and other combustion products generated from a tunnel fire will spread rapidly along the tunnel roof in both directions. If the tunnel roof is horizontal and ventilation is provided symmetrically with respect to fire, this spread will occur equally in both directions. In current practice, the common strategy for evacuation and fire control in the event of a fire is to impose an emergency ventilation flow to force the smoke flow to travel in downstream direction and therefore to create a safe escape route 
upstream clear of smoke. The term of "critical velocity" means the minimum air velocity required to prevent any smoke to move against the ventilation flow. The design of tunnel ventilation systems may be dominated by this emergency flow criterion.

The values of the air velocities required to control the smoke movement in horizontal tunnels have been studied both experimentally and theoretically. A comprehensive review of the open literature on the control of smoke movement from fires in tunnels is given by Lea [1]. Current design methods for tunnel emergency ventilation systems are based on the sets of equations derived by applying Froude Number preservation combining with some the experimental data [2-6]. The most commonly used models are these proposed by Heselden [3 ] and Danziger \& Kennedy [4] which was incorporated in the U.S. Department of Transport Subway Environment Simulation Program [5]. These models suggested the value of the critical velocity for the horizontal tunnel varies with the one third power of the heat output from the fire. Oka and Atkinson [7] studied the smoke movement systematically using a small scale horizontal model tunnel with propane gas burners as fire sources. They suggested that at low rates of heat release the critical velocity does vary as the one-third power of the heat release rate, however at higher rates of heat release the dependence on the heat release rate falls off rapidly. New formulae have been proposed. Their conclusions were support by the results from the CFD simulations by Lea [8].

For a sloping tunnel in which the ventilation flow is downgrade, a greater critical velocity is expected. The effect of the tunnel slope on the critical velocity has not been studied experimentally in connection with tunnel fires. A slope correction factor was proposed in the U.S Department of Transport Subway Environment Simulation (SES) Program [5] based on the results from a study of methane rich roof layers by Bakke and Leach [9 ]. However the accuracy of this slope correction factors should be studied further for two main concerns: the first is the difference in the releasing sources for a smoke flow from a fire and the methane flow; In the methane layering experiments buoyant fluid was released at the roof level; this contrasts with a tunnel fire where some buoyancy is generated in the lower part of the tunnel and the fire plume suffers a large deflection before impinging on the roof. A quite different pattern of variation of critical velocity could be obtained for the two flows. Secondly, the density of methane is similar to that of air at about $460 \mathrm{~K}$. A typical bulk temperature at a fire site is about $650 \mathrm{~K}$, and the bulk temperature of the front of the "backlayering" smoke flow reduced rapidly against distance upstream from the fire. The effect of the bulk temperature on the slope factor should be examined further.

This work is aimed at a study of the effect of the tunnel slope on the critical velocity. A series of experimental tests has been carried out using a small model tunnel with downhill slopes between $0^{\circ}$ and $10^{\circ}$. These results extend the work of Oka and Atkinson [7] on smoke control in horizontal tunnels.

\section{EXPERIMENTAL RIG}

The schematic front view and the cross-section of the tunnel is shown in Figure 1. 


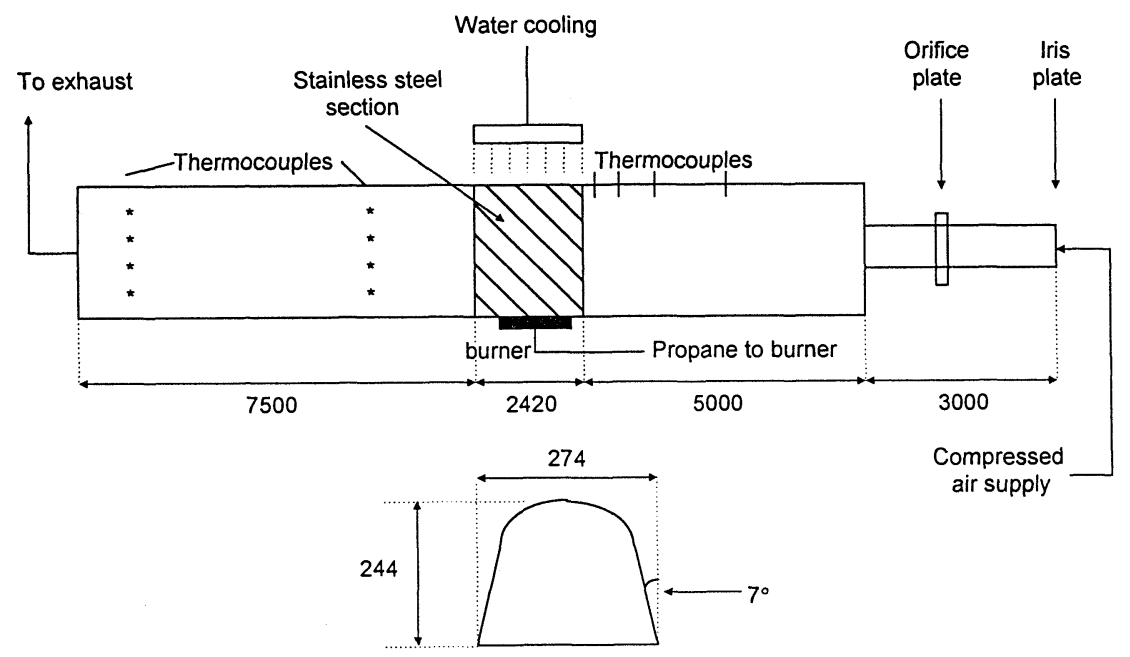

Figure 1: The schematic front view and the cross-section of the tunnel (all dimensions in $\mathrm{mm})$.

The majority of the model, including the base, was constructed from perspex (PMMA) of thickness $6.25 \mathrm{~mm}$. To prevent heat damage, the section closet to the fire was made from 18 SWG (1.25 mm thick) stainless steel. Additionally, this section was cooled throughout the tests by a water spray. As shown in Figure 1, the internal cross-section was the BS 227 Colliery arch, comprising of a semi-circular head mounted on walls splayed out at $7^{\circ}$ to the vertical, the height of the tunnel is $244 \mathrm{~mm}$. The cross-sectional area of the tunnel was $0.0569 \mathrm{~m}^{2}$. The entire tunnel, of approximate length $15 \mathrm{~m}$, was mounted on a series of brackets which in turn were attached to wall-mounted frames. These brackets could be moved up or down sufficiently to allow the inclination of the tunnel to be varied from $0^{\circ}$ to $10^{\circ}$ to the horizontal. In all tests, the tunnel was inclined so the direction of the ventilation was downgrade.

Propane gas was used as a fuel, metered through a rotameter. This was introduced via a $106 \mathrm{~mm}$ diameter porous bed burner with its top surface set flush with the tunnel floor. The propane flow rate was varied between 2 and 10 litres per minute, producing fires of 2.8, 7.1 and $14.1 \mathrm{~kW}$, respectively. These fire sizes correspond to fires of approximately 5 to 30 MW in a tunnel of diameter around $5 \mathrm{~m}$ when the scaling procedure was applied. They thus represent typical vehicle fire sizes. All products of combustion were exhausted to atmosphere at the downstream end of the tunnel.

The ventilation air supply to the tunnel was channelled in through a $101.6 \mathrm{~mm}$ steel pipe fitted with an orifice plate of throat diameter $71.8 \mathrm{~mm}$, constructed in accordance with BS 
system can be found in reference [7,11-12]. The orifice plate provides a useful method of determining the total volumetric flow of air, and velocities of the tunnel air ventilation flow are calculated by dividing the volumetric flow by the tunnel cross-sectional area.

Any upstream "back layering" flow of hot gases was detected by using K-type stainless steel sheathed thermocouples of diameter $0.25 \mathrm{~mm}$. Thermocouples were fixed $10 \mathrm{~mm}$ below the roof at distance equal to $1,3,5$ and 10 times tunnel heights upstream of the centre of the fire. Two array of 8 thermocouples each were also placed at distances of approximately 8 and 19 times tunnel heights downstream of the fire, respectively.

\section{EXPERIMENTAL RESULTS}

The critical velocities versus the tunnel slope are shown in Figure 2. The values of the critical velocities which would prevent any "back layering" flow past the fire were obtained by extrapolating the results to 0 tunnel height. The ventilation velocities required to control the length of the "back-layering" flow to 1,3,5 and 10 times of the tunnel heights have been examined systematically, and the experimental results are presented in Figure 3. Figure 4 shows an example of extrapolation of the results to 0 tunnel height to obtain the critical velocity.

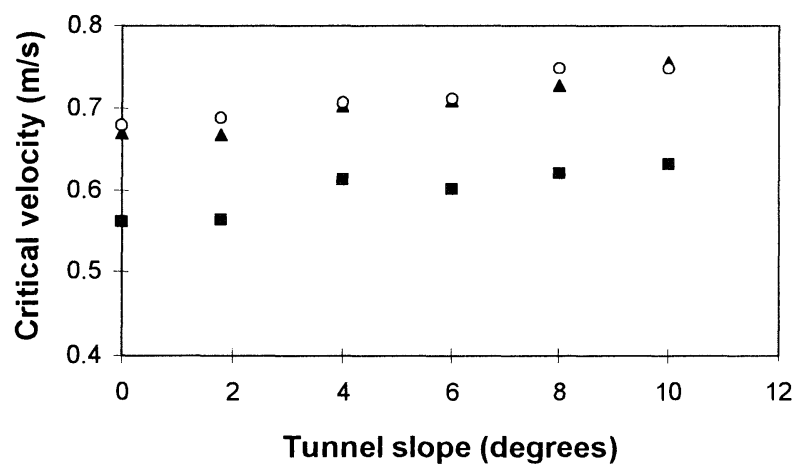

Figure 2: The critical velocities versus the tunnel slope.

Down stream temperature profiles at distances equal to 8 and 19 tunnel heights are shown in Figure 5 . 

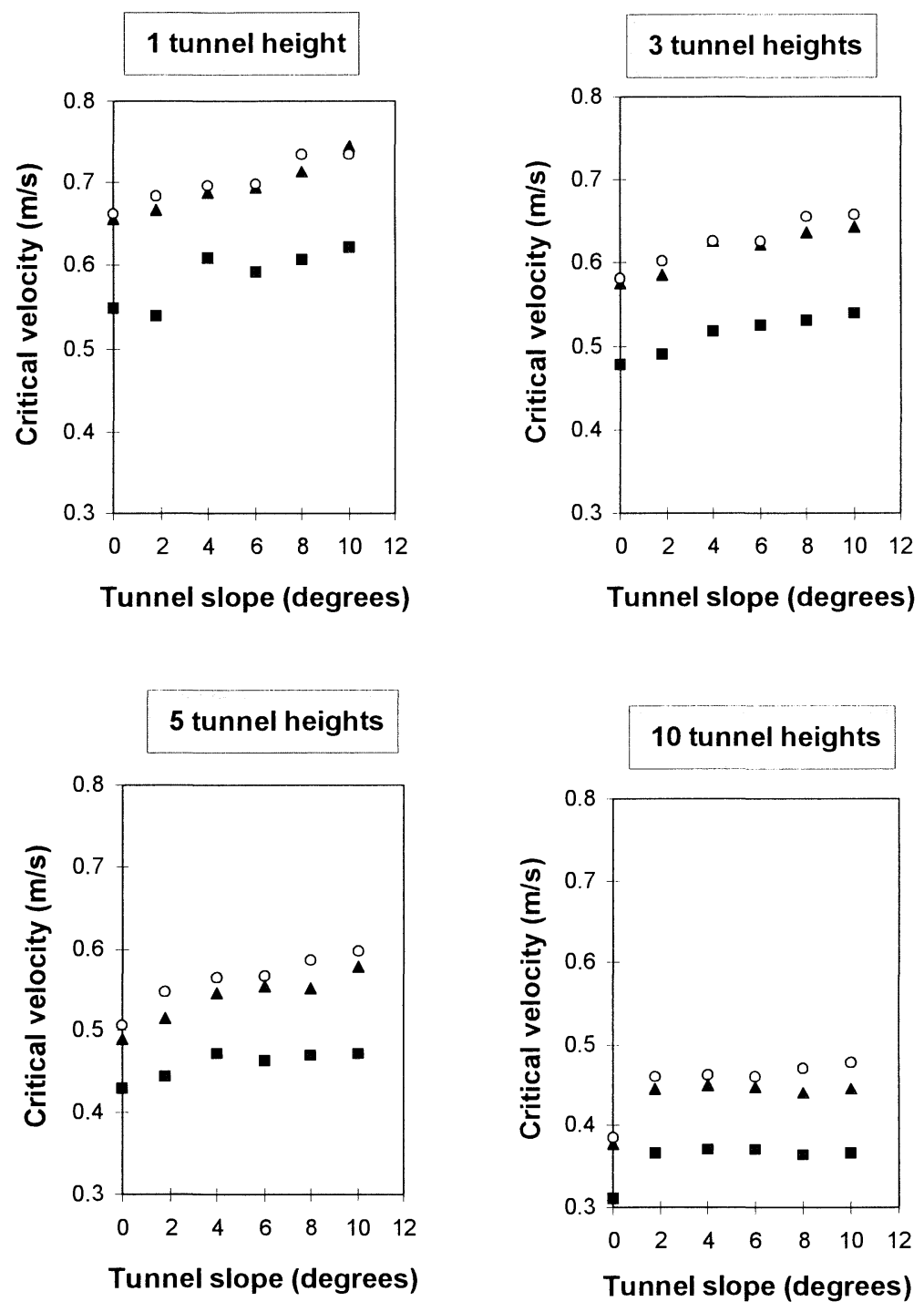

$2 \mathrm{l} /$ min propane $\left(2.8 \mathrm{~kW}, \mathrm{Q}^{*}=0.088\right)$
1 $\mathrm{l} / \mathrm{min}$ propane $\left(7.1 \mathrm{~kW}, \mathrm{Q}^{*}=0.22\right)$

o $10 \mathrm{l} / \mathrm{min}$ propane $\left(14.1 \mathrm{~kW}, \mathrm{Q}^{*}=0.44\right)$

Figure 3: The ventilation velocities required to control the length of the "back-layering" flow to $1,3,5$ and 10 times of the tunnel heights. 


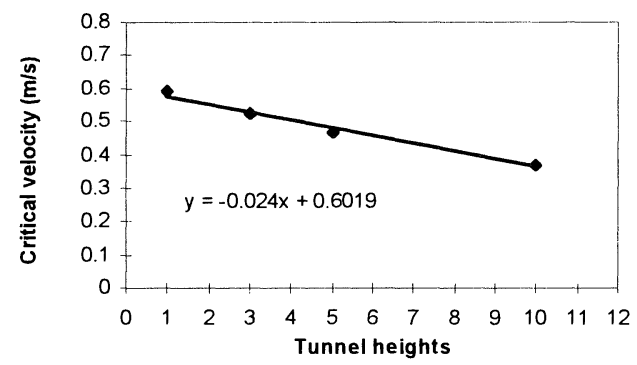

Figure 4. Using the best fitted line extrapolating experimental measurement to 0 tunnel height to obtain the critical ventilation velocity of preventing any "back-layering" flow. The propane flowrate was 2 litres $/ \mathrm{min}$, the tunnel slope was $6^{\circ}$.

Tunnel slope:
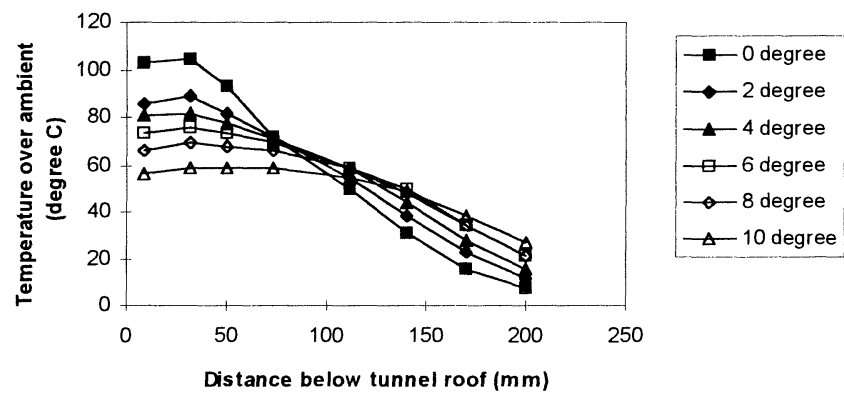

a). Temperature profile at the cross-section of 8 tunnel heights downstream of the fire.

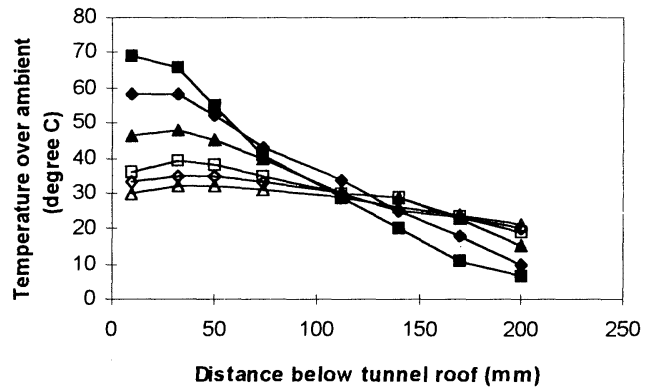

b). Temperature profile at the cross-section of 19 tunnel heights downstream of the fire.

Figure 5: Downstream temperature profiles for tunnel slopes between $0^{\circ}$ and $10^{\circ}$, the propane flowrate was 2 litres $/ \min \left(Q^{*}=0.088\right)$, and the longitudinal ventilation velocity was $0.375 \mathrm{~m} / \mathrm{s}$. 


\section{DISCUSSION}

\subsection{Slope Correction Factor to the Critical Velocity}

The ratios of the critical velocity in sloping tunnel to that in horizontal tunnel are plotted against the slope in Figure 6 . The results suggest that the critical velocity for downhill slopes in the range from $0^{\circ}$ to $10^{\circ}$ can be expressed as the following:

$$
V(\alpha)=V_{o} \times[1+0.014 \alpha]
$$

where $V_{o}$ is the critical velocity when the tunnel is at level. $\alpha$ is the tunnel slope in degrees. This is equivalent to

$$
V(\theta)=V_{0} \times[1+0.008 \theta]
$$

where $\theta$ is the absolute value of the tunnel slope expressed as a percent.

The slope correction factor obtained in this work is different from that recommended in the U.S. Department of Transport Subway Environment Simulation (SES) Program to predict the critical velocity in sloping tunnels [5], which is given as:

$$
\mathrm{V}(\theta)=\mathrm{V}_{\mathrm{o}} \times\left[1+0.0374 \theta^{0.8}\right]
$$

The SES correction factor is also shown in Figure 6. Comparisons show that the SES correction factor is higher than that obtained from the current experimental tests expressed in Equations 1 \& 2.

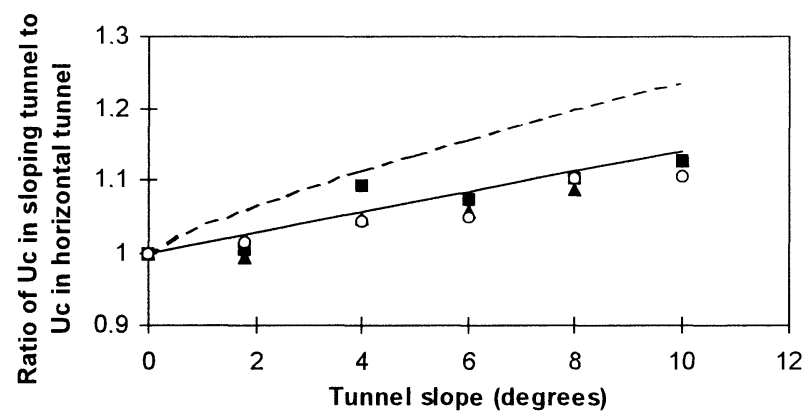

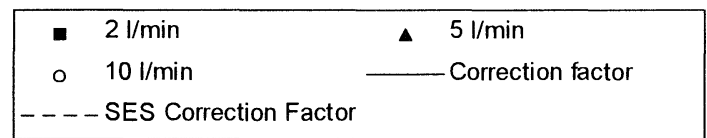

Figure 6: The ratios of the critical velocity in sloping tunnel to that in horizontal tunnel versus the tunnel slope. 
Figure 3 shows the air velocities required to control the "back layering" length of smoke gases upstream from the fire at $1,3,5$ and 10 times of the tunnel heights. It is clearly shown that the velocity required to control the "back layering" length at 1 and 3 times of the tunnel heights increase steadily with the tunnel slope. However When the backing-up length is controlled at 5 or 10 times of the tunnel heights, the air velocity required increases markedly when the slope is changed from $0^{\circ}$ to $4^{\circ}$, then it almost become independent of the slope. This change of pattern in air velocity versus tunnel grade could be determined by the characteristics of the smoke flow in the tunnel which could be considered as a gravity current.

When the fire seat is located in the low part of the tunnel, buoyant plume of the combustion products, smoke and hot gases resulted from the fire will rise and impinge the tunnel roof, then the spreading of the hot smoke along the roof will take form of a gravity current which has the characteristic features of a deep head at the leading edge, followed behind by a shallower layer. Britter and Linden[13] studied the motion of a gravity current travelling down an inclined flat surface, they reviewed that the travelling speed of the current front are sensitive to small changes in the slope angle when the slope is less than $5^{\circ}$, and the front speed is much less dependent on the slope when the grade is greater than $5^{\circ}$. The results of CFD simulation by Woodburn [14] also demonstrate this transformation in the characteristics of the gravity current. This may indicate the upstream fire generated smoke flow behaves as gravity current when the length of the flow is greater than 5 times of the tunnel heights, and when the flow is less than 5 times of the tunnel height, the flow is strongly influenced by the impingement and deflection at the tunnel roof. The flow will be studied further using CFD simulation in the future.

\subsection{Effect of the Bulk Temperature}

The bulk temperature of the smoke front could also contribute to the characteristics of the smoke "back-layering" flow. As shown in Figure 7, the temperature of the front of the upstream smoke flow reduces rapidly as the "back-layering" length increasing, therefore the dynamic strength of the head of the smoke flow reduces. Figure 8 shows the temperature distribution inside the smoke layer when length of the "back-layering" layer is 10 times the tunnel heights. The "back-layering" smoke gases cold down rapidly.

There is no straightforward way to test the influence of the bulk temperature of the smoke layer. To examine the effect, a few tests were carried out using the same tunnel set up at level, but with 4 heaters of $1.5 \mathrm{~kW}$ each installed on the roof of the section upstream from the fire as shown in Figure 9. The results as shown in Figure 10 indicates that the air velocity required to control the position of the smoke layer reduces if the upstream fresh air is heated by the heaters, and however when the "back-layering" smoke layer is heated, the air velocity required increases. Further study will be carried out to test the effect of the bulk temperature of the smoke flow. 


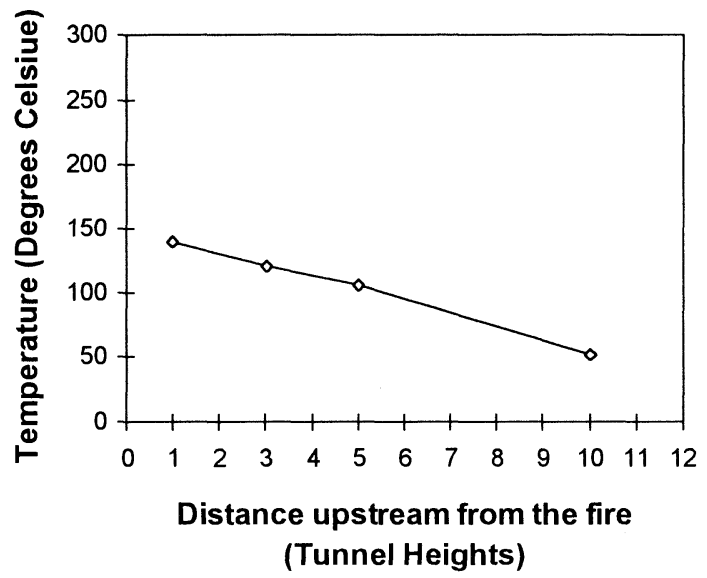

Figure 7. The temperature of the front of the upstream smoke flow versus the length of the "back-layering" flow. The propane flow rate is $10 \mathrm{l} / \mathrm{min}$, the tunnel slope is $10^{\circ}$.

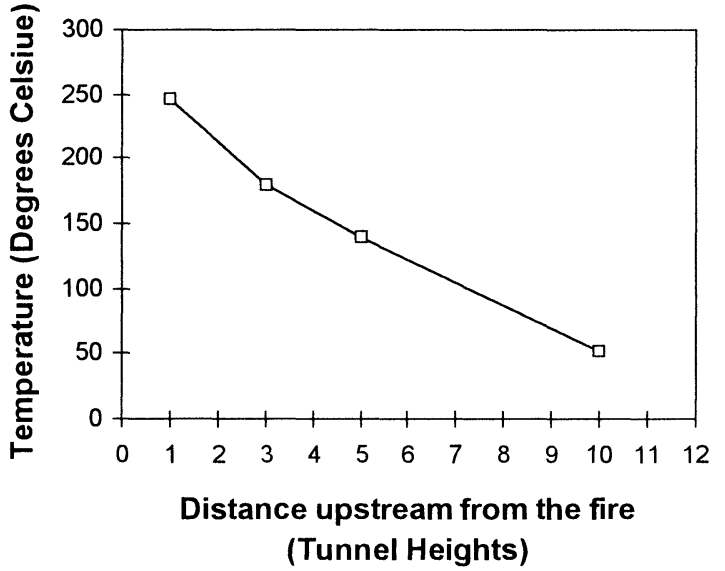

Figure 8. The temperature distribution inside the smoke layer, the length of the "backlayering" flow is 10 times the tunnel heights. The propane flow rate is $10 \mathrm{l} / \mathrm{min}$, the tunnel slope is $10^{\circ}$. 


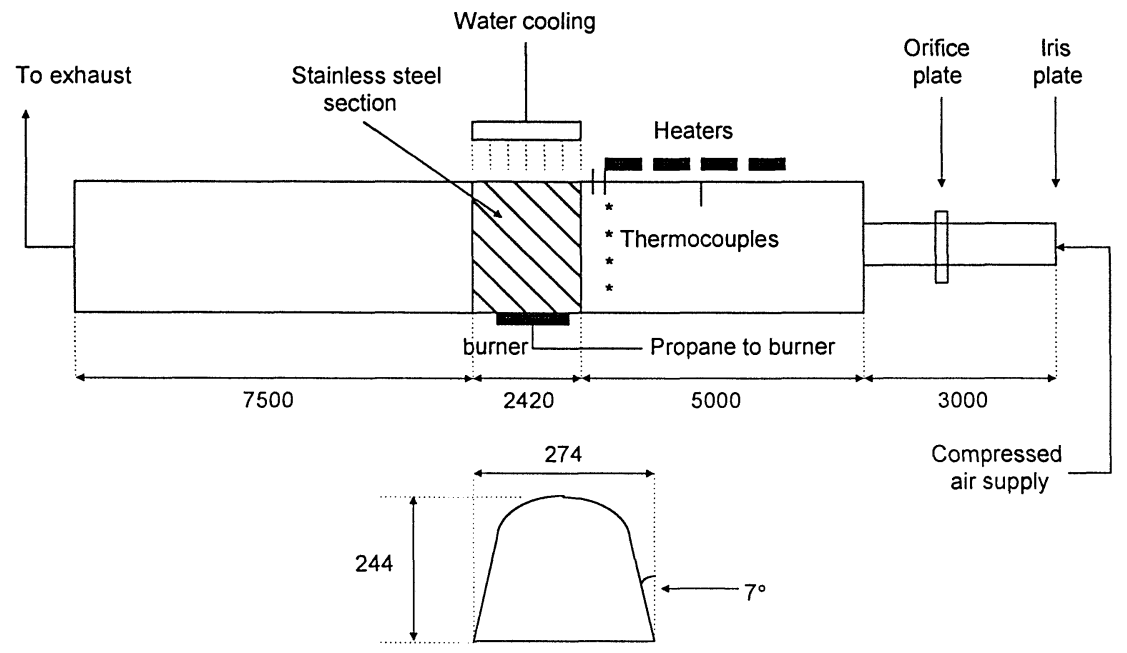

Figure 9: The schematic front view and the cross-section of the tunnel with roof heaters (all dimensions in $\mathrm{mm}$ ).

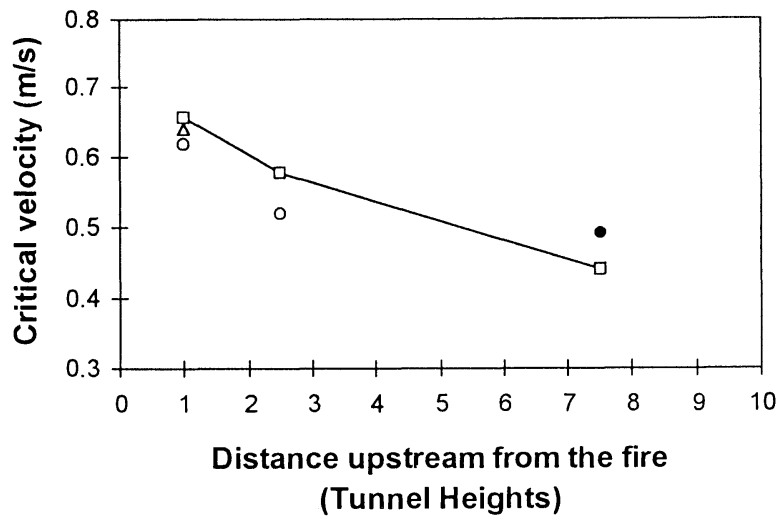

$\square-$ No heating

$\Delta$ Heating the air with one haeter

- Heating the air with 4 heaters

- Heating the smoke flow

Figure 10: The air velocity required to control the position of the smoke layer in the tunnel with heated tunnel roof. 


\section{CONCLUSIONS}

This work showed that the effect of slope on critical velocity to control the smoke flow in tunnel fire is modest. The critical velocity in slope tunnel can be obtained by modifying that in corresponding to the horizontal tunnel with a grade correction factor. Oka and Atkinson suggested dimensionless formulae for calculation of the critical velocity in tunnel fires. This work extended their results to include sloping tunnels. The formulae to estimate the critical velocity for downhill slopes in the rang $0^{\circ}$ to $10^{\circ}$ are suggested in the following:

$\mathrm{V}_{\text {critical }}=[\mathrm{g} \mathrm{H}]^{\frac{1}{2}} \times \mathrm{V}_{\max }^{*} \times\left[\frac{\mathrm{Q}^{*}}{1.2}\right]^{\frac{1}{3}} \times[1+0.014 \alpha]$ for $\quad \mathrm{Q}^{*} \leq 0.12$

$\mathrm{V}_{\text {critical }}=[\mathrm{g} \mathrm{H}]^{\frac{1}{2}} \times \mathrm{V}_{\max }^{*} \times[1+0.014 \alpha] \quad$ for $\quad \mathrm{Q}^{*}>0.12$

or :

$\mathrm{V}_{\text {critical }}=[\mathrm{g} \mathrm{H}]^{\frac{1}{2}} \times \mathrm{V}_{\max }^{*} \times\left[\frac{\mathrm{Q}^{*}}{1.2}\right]^{\frac{1}{3}} \times[1+0.008 \theta]$ for $\mathrm{Q}^{*} \leq 0.12$

$\mathrm{V}_{\text {critical }}=[\mathrm{g} \mathrm{H}]^{\frac{1}{2}} \times \mathrm{V}_{\max }^{*} \times[1+0.008 \theta] \quad$ for $\quad \mathrm{Q}^{*}>0.12$

Where

$\mathrm{Q}^{*}=\frac{\mathrm{Q}}{\rho_{\mathrm{o}} \mathrm{C}_{\mathrm{p}} \mathrm{T}_{\mathrm{o}} \mathrm{g}^{\frac{1}{2}} \mathrm{H}^{\frac{2}{5}}}$

Q is the convective heat release rate, $\mathrm{kW}$.

$\rho_{o} \quad$ is the density of the flow, $\mathrm{kg} / \mathrm{m}^{3}$.

$\mathrm{C}_{\mathrm{p}}$ is the heat capacity of the inflow at constant pressure, $\mathrm{kJ} / \mathrm{kg} \mathrm{K}$.

$\mathrm{T}_{\mathrm{O}} \quad$ is the absolute temperature of the inflow, $\mathrm{K}$.

$\mathrm{g} \quad$ is the gravitational acceleration, $\mathrm{m} / \mathrm{s}^{2}$.

$\mathrm{H}$ is the tunnel height, $\mathrm{m}$.

$\alpha \quad$ is the tunnel slope in degrees.

$\theta \quad$ is the tunnel slope expressed as a percent.

$\mathrm{V}_{\max }^{*}$ is taken for consideration of different fire sources with and without tunnel

blockages, and is discussed by Oka and Alkinson [7]. For a fire on the floor of a tunnel without significant blockage, the value of $V_{\max }^{*}$ varies from about 0.35 for a fire that is much narrower that the width of the tunnel to 0.31 for a fire that extends to the full width of the tunnel. 


\section{References}

1. Lea, C. J., Bettis, R. J. and Jagger, S. F. , "A Review of Available Data and Models for Tunnel Fires", the Health and Safety Laboratory Report IR/L/FR/94/12, the Health and Safety Executive, U.K.

2. Thomas, P. H., "The Movement of Smoke in Horizontal Passages Against an Air Flow", Fire Research Station Note No. 723, Fire Research Station, U.K., Sept. 1968.

3. Heselden, A. J. M., "Studies of Fire and Smoke Behaviour Relevant to Tunnels", Proc of the 2nd Int. Symp. of Aerodynamics \& Ventilation of Vehicle Tunnels, Paper JI, 1976.

4. Danziger, N. H. and Kennedy, W. D., "Longitudinal Ventilation Analysis for the Glenwood Canyon Tunnels", Proc. of the 4th Int. Symp. Aerodynamics and Ventilation of Vehicle Tunnels, pp 169-186, 1982.

5. Parsons Brinkerhoff Quade \& Douglas, Inc., "Subway Environmental Design Handbook Volume II Subway Environment Simulation (SES) Computer Program Version 3 Part I: User's Manual, prepared in draft for the U.S. Department of Transportation, October 1980.

6. Kennedy, W. D. and Parsons Brinckerhoff, "Critical Velocity: Past, Present and Future", paper presented in the One Day Seminar of Smoke and Critical Velocity in Tunnels, London, 2 April 1996.

7. Oka, Y. and Atkinson, G. T, " Control of Smoke Flow in Tunnel Fires", Paper accepted to be published in the Fire Safety Journal, 1996.

8. Lea, C. J. "CFD Modelling of the Control of Smoke Movement from Tunnel Fires Using Longitudinal Ventilation", the 1st Int. Symp of IAFSS, August, ETH, Zurich, 1995.

9. Bakke, P. and Leach, S. J., "Methane Roof Layers", Safety in Mines Research Establishment Report No. 195, Buxton, U.K., 1960.

10. "Measurement of Fluid Flow in Closed Conduits", British Standard 1042, 1991

11.Stoddard, J. P., "An Experimental Investigation into the Effect of Gradient on the Control of Smoke Flow from Tunnel Fires", thesis of M.Eng. Project, Dept. of Mechanical and Process Engineering, Sheffield University, May 1996.

12.James, P. "Control of the Smoke Flow in Tunnel Fires -Effect of a Heated Roof on the Critical Ventilation Velocity", thesis of M.Eng. Project, Dept. of Mechanical and Process Engineering, Sheffield University, May 1996.

13.Britter, R. E. and Linden, P. F., "The Motion of a Gravity Current Travelling Down an Incline", J. Fluid Mech., Vol:99, P531, 1980.

14.Woodburn, P., "Computational Fluid Dynamics Simulation of Fire-generated Flows in Tunnels and Corridors", Ph.D. thesis at the University of Cambridge, Pembroke College.

\section{Acknowledgements}

The authors would like to thank Mr. D. Bagshaw and Mr. Belfield of the Health and Safety Laboratory for their work in building the equipment used in this work, and James Stoddard and Peter James would like to express their sincerely thanks to Dr. G. T Atkinson for his support and help to their M.Eng. projects. 